\title{
Lazer Doppler Flovmetre
}

\author{
Derya Güler*, Emine Șen Tunç
}

DOI: $10.17944 /$ mkutfd.538803

Derya Güler: Dr. Öğr. Üyesi, Bolu Abant İzzet Baysal Üniversitesi, Diș Hekimliği Fakültesi, Pedodonti Anabilim Dalı, Bolu

Email: dt_deryad@hotmail.com

ORCID iD: https://orcid.org/0000-0001-8119-1125

Emine Șen Tunç: Prof. Dr., Samsun Ondokuz Mayıs Üniversitesi, Diş Hekimliği Fakültesi, Pedodonti

Anabilim Dalı, Samsun

Email: sentunc@yahoo.com

ORCID iD: https://orcid.org/0000-0002-4397-8952

Bildirimler/Acknowledgements

Yazarlar bu makale ile ilgili herhangi bir cıkar çatıșması bildirmemișlerdir.

The authors declare that they have no conflict of interests regarding content of this article.

Yazarlar bu makale ile ilgili herhangi bir finansal destek bildirmemișlerdir.

The Authors report no financial support regarding content of this article.

$\therefore$ Sorumlu Yazar/Corresponding Author

Gelis/Received: 12.03.2019

Kabul/Accepted: 24.05 .2019

e-ISSN: 2149-3103

Web: https://dergipark.org.tr/mkutfd
Öz

Lazer Doppler Flovmetre

Pulpa vitalitesinin değerlendirilmesi diș hekimliği pratiğinde teșhis așamasında kritik bir öneme sahiptir. Geleneksel pulpa canlılık test yöntemleri pulpal innervasyona dayalıdır ve bazen yanlış pozitif ya da yanlış negatif cevaplar verebilmektedir. Ayгıca, bu yöntemler hastanın uyaranlara cevabını değerlendirdiklerinden subjektif testlerdir. Pulpa vitalitesi, kan desteğinin doku içinde bulunduğu anlamına gelmektedir. Son zamanlarda pulpa vitalitesinin belirlenmesinde pulpal kan akımının yarı nicel kaydına izin veren non invaziv ve ağrısız elektro optik bir teknik olan Lazer Doppler Flovmetre'nin kullanılmaya bașlandığı görülmektedir.

Anahtar Kelimeler: Diș hekimliği, Lazer Doppler Flovmetre, Pulpal kan akımı, Vitalite testi

\section{Abstract}

Laser Doppler Flowmetry

Evaluation of pulp vitality is critical importance in the diagnostic process in dentistry practice. Conventional pulp test methods are based on pulpal innervation and sometimes give false positive or false negative responses. In addition, these methods are subjective tests because they evaluate the response of the patient to stimuli. Pulp vitality means that blood support is present in the tissue. Recently, it has been observed that Laser Doppler Flowmeter, a non-invasive and painless electro-optic technique allowing semi-quantitative recording of pulpal blood flow, is being used in the determination of pulp vitality.

Keywords: Dentistry, Laser Doppler Flowmetry, Pulpal blood flow, Vitality test

\section{Giriş}

Pulpanın vitalitesinin değerlendirilmesi diș hekimliği pratiğinde teșhis aşamasında kritik bir öneme sahiptir. Pulpa vitalite testleri, özellikle travmatik yaralanmalar sonrasında pulpanın sağlık durumunu görüntülemede oldukça değerlidir. Termal ve elektrik gibi geleneksel pulpa test metodları innervasyona dayalıdır ve bazen yanlış pozitif ya da yanlış negatif cevaplar verebilmektedir. Ayrıca, bu yöntemler hastanın uyaranlara cevabını değerlendirdiklerinden subjektif testlerdir (1). Pulpa vitalitesi, kan desteğinin doku içinde bulunduğu anlamına gelmektedir. Son zamanlarda pulpa vitalitesinin belirlenmesinde pulpal kan akımının (PKA) yarı nicel kaydına izin veren non invaziv ve ağrısız elektro optik bir teknik olan Lazer Doppler Flovmetre'nin (LDF) kullanılmaya başlandığı görülmektedir (2).

Tıp literatürüne ilk olarak Yeh ve Cummins' in çalışmaları ile katılan LDF; deri, retina, renal korteks gibi doku sistemlerindeki kan akımını değerlendirmek için geliștirilmiş ve daha sonrada tavşan retinasındaki kan alımını değerlendirmek amacıyla kullanılmıştır $(3,4)$. Diş hekimliğinde ise, ilk kez Gazelius ve ark. tarafından dişin canlılığının ve travmaya uğramış dişlerin yeniden damarlanmasının ölçülebildiğini göstermek amacıyla kullanılmış ve canlı dişlerde kalp atışına yakın bir salınım olduğu, canlı olmayan dişlerde ise bu salınımın olmadığı belirtilmiştir (5).

\section{Lazer Doppler Flovmetre Cihazının Yapısı}

LDF, temel olarak hareketli bir objeden yansıyan radyasyonun frekansında oluşan değişikliğin ölçülmesine dayanır. Bu cihazlar temel olarak lazer ışın kaynağı, fotodedektör, fiber optik düzen ve sinyal işlemci olmak üzere dört ana parçadan oluşmaktadır. Diod lazerlerden üretilen monokromatik lazer ışınlar lens aracılığıyla optik fibere iletilir. Dokudan geri saçılan ışınları fotodetektöre taşıyan toplayıcı fiber ve ışını dokuya taşıyan verici fiber ölçüm probu içerisinde bulunur. Işın demeti bir prob yardımıyla dokuya iletildiğinde, ışının bir kısmı dokudan yansırken bir kısmı da doku 
tarafından absorbe edilir. Işı̆̆ı yansıtan statik nesneler dalga boyunda herhangi bir değişikliğe neden olmazken, ışığı yansıtan hareket eden kan hücreleri Doppler kayması oluşturur. Doppler kaymasına sebep olan ışın demeti sonucu sinyaller oluşur. Bu sinyallerin sonucunda edinilen değerler "perfüzyon", "volt", "flow" veya "flux" olarak tanımlanır (6).

\section{Lazer Doppler Flovmetre Ölçümlerinden}

\section{Elde Edilen Veriler}

Dalga boyundaki değişikliklerin boyutu ve frekans dağ1lımı, kan hücrelerinin hızı ve sayısıyla direkt olarak bağlantılıdır. Ancak hücrelerin hareket ettiği yönü göstermez. Bu ışın demetinin doku içerisindeki yaygın saçılımı nedeniyledir. Yani prob ucunun yakınında hareket eden bir hücre ile prob ucundan uzakta hareket eden bir hücrenin sinyal değişimine olan etkileri aynıdır. Hareketli kan hücrelerinin konsantrasyonu (HKHK); lazer ışının hedef aldığı bölgedeki ışını absorbe eden hareketli kırmızı kan hücrelerinin miktarıdır. "Conc" terimi ile eş anlamlı olarak kullanılmaktadır. Bu terim, cihazın ölçüm aralığında olan ve Doppler kayması oluşturan tüm hücreleri ifade eder (6-8).

HKHK ile hücrelerin hız değerlerinin ortalamasının çarpımı ile Perfüzyon Ünitesi (PU) elde edilir (9). Cihazın verdiği perfüzyon değeri mutlak değildir. Yani perfüzyon değeri, belli bir sürede, belli bir hacimdeki dokudan geçen gerçek hücre sayısı gibi fizyolojik bir tanımlama yapmaz. Aynı bireyin farklı bölgelerinde periferal perfüzyonda fizyolojik farklılıklar gözlenmektedir. Ayrıca, kapiller yoğunluk ve permeabilitenin lokal doku bölgelerinde küçük mesafeler arasında ve zamana bağlı olarak değişiklikler göstermesi perfüzyon ünitelerinin fizyolojik açıdan değerini sınırlamaktadır (9). LDF cihazlardan elde edilen değerlerle, birim dokudan geçen kan miktarını belirtecek şekilde kalibrasyon yapılamayacağı için cihazların standardizasyonunun sağlanması gerekmektedir. Bu amaçla, Perimed firması tarafından, $20^{\circ} \mathrm{C}$ de $\% 0,5$ yoğunluktaki $0,48 \mathrm{~m}$ çaplı polistren mikrokürecikleri içeren Motility Standart solüsyonu geliştirilmiştir. Sürekli hareket halinde olan bu mikroküreciklerin bu hareketine Brownian hareketi denir ve aynı standarttaki tüm süspansiyonlar için eşit değerdedir. Fizyolojik anlamı olmayan bu hareket firma tarafindan 250 PU olarak tanımlamıştır. Bu nedenle, perfüzyon değerleri farklı bir cihazla kıyaslanabilir, ancak mutlak değildir (8).

LDF cihazlarından elde edilen bir diğer veri fotodetektöre geri dönen ışığın sayısıdır ve total backscatter (TB) olarak tanımlanmaktadır. TB değerinin yüksek olması ve temiz bir sinyal üretilebilmesi için, arka plan gürültüsü minumuma indirilmelidir (8). TB değeri lazerin gücüne, doğrultusuna, odaklamasına, probdaki fiberlerin birbiriyle olan mesafesine ve probdaki fiberlerin toplam alıcı alanına bağlıdır.

\section{Lazer Doppler Flovmetre Okuma}

\section{Sonuçlarını Etkileyen Faktörler}

\subsection{Lazer Işı̆̆ının Karakteristiği}

Lazer ışığının karakterinin değişikliği önemli miktarda flux sinyalini etkilemektedir. Çalışmalar, dar ve $3 \mathrm{kHz}$ bant genișlikli filtreyi ile 810 - 633 nm lazer kaynağının kullanımını desteklemektedir $(10,11)$. Diş dokusuna daha iyi penetre olduğundan yüksek dalga boylu lazerler daha yüksek flux okumaları vermesine rağmen, pulpal olmayan akım sinyallerinin okunması ve bu nedenle de nonvital dişlerin vital dişler gibi sinyaller vermesi riskini arttırır (12).

\subsection{Prob Açılaması}

Fiber optik kablolarda taşınan ışının fibere girebilmesi için kritik açıdan daha küçük bir eğimle gelmesi gerekir. Teorik olarak tamamen düz duran bir fiber kablonun içine 25 derece açıyla giren bir ışın diğer ucundan yine 25 derece açıyla çıkmaktadır. Prob açılamasının LDF sonucu üzerine etkisinin değerlendirildiği çok az çalışma vardır (13).

\subsection{Prob Pozisyonu}

Prob pozisyonunun gingivaya yakın tutulduğu ölçümlerde, periodontal dokulardan nonpulpal sinyaller eklendiğinden daha yüksek flux değerleri elde edildiği bildirilmiştir (11). Benzer şekilde, Akpınar ve ark.'nın yaptıkları çalışmada prob dişin insizal üçlü bölgesinde tutulmuş ve daha düşük değerler elde etmiş (14). Bu bulguların tersine, Odor ve ark. prob pozisyonunun ışık geçişini etkilemediğini göstermiştir (13).

\subsection{Prob Dizaynı}

Kullanım yerlerine göre farklı LDF probları mevcuttur. Problar arasındaki farklılık, uygulama alanına uygun eksternal özellikler ya da fiber ayrımlarına göre internal özellikler gösterebilir $(11,15)$.

\subsection{Prob Tutucusunun Yapısı}

Artefaktlardan kaçınarak, pulpal vaskülaritedeki hareketli hücreleri LDF ile ölçebilmek için dişler üzerine oturan ve böylece stabilite sağlayan ve farklı zamanlarda tekrarlanabilir doğru ölçümler yapabilmeye olanak sağlayan uygun tutucuya gereksinim vardır. Stabilizatörler hazırlanırken, hastalardan alınacak ölçüler üzerinde test edilecek dişin bukkal yüzünde prob çapına uygun delik oluşturulur. Bu amaçla, silikonlar, plastikler, akrilik, kendi kendine sertleşen rezinler gibi farklı materyaller kullanılmıştır (11). 


\subsection{Pulpal Olmayan Sinyaller}

Özellikle periodontal dokulardan kaynaklanarak kontamine olmuş pulpal sinyallerin gerçek pulpal flux değerlerini yanılttığı gösterilmiştir $(16,17)$. Önlem alınmadığı durumlarda, LDF sinyallerinin büyük kısmınım destek dokulardan geleceği ileri sürülmektedir (18). Ingolfsson ve ark. pulpal kan akımının belirlenmesine tespit edilen sinyallerin \%45-60'ının pulpa kaynaklı olmadığını göstermişlerdir (7).

Devital dişlerde çıkış sinyali vital dişlere göre kayda değer miktarda düşüktür ve bu değer sıfır varsayılır. Polat ve ark. vital ve kök kanal tedavisi yapılmış dişlerden kayıt alarak kan akımlarını LDF ile karşılaştırdıkları çalışmalarında, rubber-dam uygulaması gibi önlemler alınmadığı takdirde sinyallerin büyük bir kısmının pulpa dışı dokulardan geldiğini bildirmişlerdir (17). Bu nedenle ölçümü yapılan diş kronun izole edilmesi sonuçların güvenilirliği açısından oldukça önemlidir. Komşu dokuların sinyallerinin katkısını önlemede; rulo pamuklar (18), periodontal patlar (19) ve rubber-dam uygulaması $(18,20)$ gibi pek çok yöntem denenmiştir. Akpınar ve ark. periodontal pat ile yapılan izolasyon işleminin pulpal kan akımı ölçüm değerlerinde \%63 oranında azalma sağlandığını bildirmişlerdir (19). Rubber-dam uygulamasında ise, bu azalma oranının \%69-73 arasında değiştiği bildirilmiştir $(18,20)$. Rubber-dam kullanımı tercih edildiğinde opak ve kalın örtülerin kontaminasyonu daha çok engelleyeceği ileri sürülmüştür (18).

\subsection{Diş Tipi}

LDF ölçümlerinin ön dişlerde kullanıldığı pek çok çalışma olmasına rağmen, arka grup dişlerde kullanımının az sayıda çalımada değerlendirildiği görülmektedir (21-24). Yanpiset ve ark., keserler ile premolar üzerine yaptıkları çalışmalarında, LDF'nin etkinliği ile diş tipi arasında bir önemli bir fark olmadığını bildirmişler, ancak birinci ile ikinci preomolar arasında belirgin bir fark gözlemlemişler$\operatorname{dir}(25)$.

\section{8. İlaç Kullanımı}

Capsaisin (26) ve antihipertansif ilaçların yanı sıra nikotin tüketiminin de (27) PKA'da değişime neden olabileceği bildirilmiştir.

\subsection{Isı Değişimi}

Farklı zamanlarda yapılan ölçümlerin karşılaştırılabilmesi için, derideki kan perfüzyonu ölçümlerinin 1sı-kontrollü bir odada ve eşit ortam ısılarında yapılması önerilmektedir $(28,29)$.

\subsection{0. Ölçüim Derinliği}

Ölçüm derinliği, genellikle dokuya gelen yüzey ışığının penetre olduğu ve yüzeye geri geldiği derinliği tarif etmektedir. Ölçüm derinliğinin büyüklüğü, kapiller yatağın yapısına yoğunluğuna, ışığın dalga boyuna ve probdaki fiberlerin birbiri arasındaki mesafeye bağlıdır. Cihazın ölçüm derinliği yaklaşı $1 \mathrm{mmdir}$. Daimi dişte mine ve dentin kalınlığı genellikle 2 - 3,5 mm olmasına rağmen mine-dentin tabakaları aşılarak, bir dişin pulpasının kan akımı ölçülebilmektedir. LDF'nin bu derinlikteki pulpanın kan akımını saptama becerisi dentin tübüllerinin ışık rehberliği etkisine dayandırılmaktadır (8).

\section{Diş Hekimliğinde Kullanım Alanları}

LDF, diş hekimliğinin tüm dallarında kullanım alanı bulmuştur. LDF ile pulpa, dişeti ve kemikteki kan akımı ölçümü yapılabilmektedir.

Pulpal vitalitenin değerlendirilmesi, elektriksel ve termal uyaranlara pulpanın cevabının görüntülenmesinde kullanılmıştır. Sıcak ve soğuk uygulamanın pulpal kan akımına etkisinin LDF ile incelendiği bir çalışmada, bu uyarıların pulpal kan akımını etkilediğini bildirilmişlerdir (28, 30).

Travmatik yaralanmalar sonrası PKA'nın ölçülmesinde kullanılabilir. Travmaya uğramış dişlerin innervasyonları hasara uğrayabilir ve kan akımı ve vitalite fonksiyonları devam etmesine rağmen pulpa testlerine yanlış cevap verebilir. Oysaki LDF'nin bu dişlerde güvenle kullanılabileceği ileri sürülmektedir (2, 31-33).

Çocuklarda pulpa vitalitesini tespit etmekte kullanılabilir. Hassasiyet testleri çocuklarda güvenilir değildir, çünkü bu tür testler subjektiftir ve hastanın cevabına bağlıdır. LDF'nin hem süt hemde genç daimi dişlerin pulpal kan akımını ölçmek için uygun bir yöntem olduğu bildirilmiştir (34-36).

İnsan pulpasının kan akışındaki değişikliklerin yaşla ilişkisinin incelendiği bir çalışmada, pulpa kan akışının artan yaşla önemli derecede azaldığı gözlemlenmiştir (37).

Egzersizlerin PKA'daki etkisini görüntülemede kullanılmıştır. Egzersize bağlı pulpal ve dişeti kan akımında bir miktar değişiklikler olduğu gözlemlenmiştir (38).

Lokal ve sistemik ilaçların diş ve çevre dokulardaki kan akımı reaksiyonlarını görüntülemede kullanılabilir (39-42).

Dişler üzerine uygulanan farklı yük ve yöndeki ortodontik kuvvetlerin dişlerdeki pulpal kan akımında yaptığı değişiklikleri görüntülemede kullanılabilir (43-45).

Ortognatik cerrahi sonrası kemiksel değişikliklerin yapıldığı bölgelerdeki dişlerin PKA değerlerinin ölçülmesinde kullanılabilir (46) 
Dişlere uygulanan restoratif ajanların ve pulpa kaplama materyallerinin pulpaya etkilerinin değerlendirilmesinde kullanılabilir (47)

Dişetindeki eksternal etkenlere bağlı değişimleri görüntülemede kullanılabilir. Sigara kullanımının ya da taşkın yapılan dolguların gingival kan akımında değişikliğe neden olup olmadığı LDF kullanılarak değerlendirilmiştir (48-50).

\section{Avantajları}

LDF’ nin en büyük avantajı pulpal kan akımını ölçebilen non invaziv bir araç olmasıdır. Bunun yanı sıra; kullanımının kolay olması ve tekrarlanabilir ölçümler yapılabilir olması bir diğer güzel özelliğidir. Ayrıca, cihazdan elde edilen veriler özel bir yazılım kullanılarak bilgisayarda grafik olarak izlenebilir ve istatistiksel inceleme yapılabilir. Diğer vitalite testlerinde cevapları güvenilir bulunmayan küçük çocuklarda kullanışlıdır ve hasta kooperasyonunu kurulmasında katkı sağlar $(8,51)$.

\section{Dezavantajları - Limitasyonları}

Elde edilen değerler mutlak ve her zaman kan akımı ile doğrusal ilişkiye sahip değildir. Bireyler arasında ve hatta aynı bireyde farklı zamanlarda yapılan ölçümlerde periferal perfüzyonda fizyolojik farklılıklar gözlenmektedir (8).

Temelde ölçülen hareketli nesneler kırmızı kan hücreleridir. Ancak LDF' nin tek bir kurılma indeksine özel bir duyarlılı̆̆ı yoktur. Cihaz prob ucunda oluşan tüm hareketleri kaydeder. Bu sebeple, ölçüm sırasında probun hareketsiz kalması mühimdir. Prob hareket eder ise, kan hücrelerinden başka yapılar da Doppler kayması oluştururlar. Çevre dokulardan gelen ışınlar ve lazer stabilitesindeki bozukluk ölçümde hataya neden olabilir. Bu nedenle, sensör hareketsiz tutulmalıdır ve net bir okuma için ölçüm bölgesi ile kesintisiz bir kontakt sağlanmalıdır $(18,24)$.

Bu yöntem akut değişiklikleri belirlemek için güvenilirdir fakat doğru pozisyonu tekrarlama problemi nedeniyle uzun süreli ortodontik kuvvet uygulaması sonrasında ya da lüksasyon yaralanmalarında spontan repozisyonu takip ederken pulpal kan dolaşımının değerlendirilmesi için uygun değildir (11).

Renklenmiş dişlerdeki kan pigmentleri lazer ışını geçişini engelleyebilir. Destek dokulardan gelebilecek yanlış pozitif cevapların önüne geçebilmek için dikkat sarf edilmelidir $(17,30)$.

Yüksek oranda doğruluk sağlamasına karşın LDF ile kan akımı komplike ve zaman alıcı bir yöntemdir $(7,52)$.

\section{KAYNAKLAR}

1. J. M. Schmitt, R. L. Webber, and E. C. Walker, 'Optical Determination of Dental Pulp Vitality', IEEE Trans Biomed Eng 38,4 (1991): 346-52.

2. E. Roy, B. Alliot-Licht, S. Dajean-Trutaud, C. Fraysse, A. Jean, and V. Armengol, 'Evaluation of the Ability of Laser Doppler Flowmetry for the Assessment of Pulp Vitality in General Dental Practice', Oral Surg Oral Med Oral Pathol Oral Radiol Endod 106,4 (2008): 615-20.

3. Y_Yeh, and HZ Cummins, 'Localized Fluid Flow Measurements with an He-Ne Laser Spectrometer', Applied Physics Letters 4,10 (1964): 176-78.

4. Charles Riva, Benjamin Ross, and George B Benedek, 'Laser Doppler Measurements of Blood Flow in Capillary Tubes and Retinal Arteries', Investigative Ophthalmology \& Visual Science 11,11 (1972): 936-44.

5. B. Gazelius, L. Olgart, B. Edwall, and L. Edwall, 'Non-Invasive Recording of Blood Flow in Human Dental Pulp', Endod Dent Traumatol 2,5 (1986): 219-21.

6. Kahraman Güngör, Lazer Doppler Flowmetri (Ldf)'Nin Dişhekimliğindeki Önemi, (Gazi Üniversitesi Gazi University, 2003).

7. A. E. Ingolfsson, L. Tronstad, and C. E. Riva, 'Reliability of Laser Doppler Flowmetry in Testing Vitality of Human Teeth', Endod Dent Traumatol 10,4 (1994): 185-7.

8. B. Matthews, and N. Vongsavan, 'Advantages and Limitations of Laser Doppler Flow Meters', Int Endod J 26,1 (1993): 9-10.

9. P. A. Oberg, 'Laser-Doppler Flowmetry', Crit Rev Biomed Eng 18,2 (1990): 125-63.

10. T. M. Odor, T. F. Watson, T. R. Pitt Ford, and F. McDonald, 'Pattern of Transmission of Laser Light in Teeth', Int Endod J 29,4 (1996): 228-34.

11. E. M. Roebuck, D. J. Evans, D. Stirrups, and R. Strang, 'The Effect of Wavelength, Bandwidth, and Probe Design and Position on Assessing the Vitality of Anterior Teeth with Laser Doppler Flowmetry', Int J Paediatr Dent 10,3 (2000): 213-20.

12. S. Polat, K. Er, and N. T. Polat, 'The Lamp Effect of Laser Doppler Flowmetry on Teeth', J Oral Rehabil 32,11 (2005): 844-8.

13. T. M. Odor, T. R. Ford, and F. McDonald, 'Effect of Probe Design and Bandwidth on Laser Doppler Readings from Vital and Root-Filled Teeth', Med Eng Phys 18,5 (1996): 359-64.

14. Kerem Engin Akpınar, 'Dentin Çürüğü Bulunan Dişlerde Meydana Gelen Pulpa Kan Akim Hizindaki Değİşìliğin Laser Doppler Flowmetry (Ldf) Metodu Ile Değerlendirilmesi'.

15. A. R. Ingolfsson, L. Tronstad, E. V. Hersh, and C. E. Riva, 'Effect of Probe Design on the Suitability of Laser Doppler Flowmetry in Vitality Testing of Human Teeth', Endod Dent Traumatol 9,2 (1993): 65-70.

16. M. Ikawa, N. Vongsavan, and H. Horiuchi, 'Scattering of Laser Light Directed onto the Labial Surface of Extracted Human Upper Central Incisors', J Endod 25,7 (1999): 483-5. 
17. S. Polat, K. Er, K. E. Akpinar, and N. T. Polat, 'The Sources of Laser Doppler Blood-Flow Signals Recorded from Vital and Root Canal Treated Teeth', Arch Oral Biol 49,1 (2004): 53-7.

18. A. Hartmann, J. Azerad, and Y. Boucher, 'Environmental Effects on Laser Doppler Pulpal Blood-Flow Measurements in Man', Arch Oral Biol 41,4 (1996): 333-9.

19. K. E. Akpinar, K. Er, S. Polat, and N. T. Polat, 'Effect of Gingiva on Laser Doppler Pulpal Blood Flow Measurements', J Endod 30,3 (2004): 138-40.

20.S. Soo-ampon, N. Vongsavan, M. Soo-ampon, S. Chuckpaiwong, and B. Matthews, 'The Sources of Laser Doppler Blood-Flow Signals Recorded from Human Teeth', Arch Oral Biol 48,5 (2003): 353-60.

21. T. Sasano, D. Onodera, K. Hashimoto, M. Iikubo, S. Satoh-Kuriwada, N. Shoji, and T. Miyahara, 'Possible Application of Transmitted Laser Light for the Assessment of Human Pulp Vitality. Part 2. Increased Laser Power for Enhanced Detection of Pulpal Blood Flow', Dent Traumatol 21,1 (2005): 37-41.

22. Y. Konno, T. Daimaruya, M. Iikubo, R. Kanzaki, I. Takahashi, J. Sugawara, and T. Sasano, 'Morphologic and Hemodynamic Analysis of Dental Pulp in Dogs after Molar Intrusion with the Skeletal Anchorage System', Am J Orthod Dentofacial Orthop 132,2 (2007): 199-207.

23. H. Jafarzadeh, 'Laser Doppler Flowmetry in Endodontics: A Review', Int Endod J 42,6 (2009): 476-90.

24. N. Ghouth, M. S. Duggal, A. BaniHani, and H. Nazzal, 'The Diagnostic Accuracy of Laser Doppler Flowmetry in Assessing Pulp Blood Flow in Permanent Teeth: A Systematic Review', Dent Traumatol 34,5 (2018): 311-19.

25. K. Yanpiset, N. Vongsavan, A. Sigurdsson, and M. Trope, 'Efficacy of Laser Doppler Flowmetry for the Diagnosis of Revascularization of Reimplanted Immature Dog Teeth', Dent Traumatol 17,2 (2001): 6370 .

26. G. M. Verdickt, and P. V. Abbott, 'Blood Flow Changes in Human Dental Pulps When Capsaicin Is Applied to the Adjacent Gingival Mucosa', Oral Surg Oral Med Oral Pathol Oral Radiol Endod 92,5 (2001): 561-5.

27. J. M. Musselwhite, B. Klitzman, W. Maixner, and E. J. Burkes, Jr., 'Laser Doppler Flowmetry: A Clinical Test of Pulpal Vitality', Oral Surg Oral Med Oral Pathol Oral Radiol Endod 84,4 (1997): 411-9.

28. E. Andersen, H. Aars, and P. Brodin, 'Effects of Cooling and Heating of the Tooth on Pulpal Blood Flow in Man', Endod Dent Traumatol 10,6 (1994): 256-9.

29. H. E. Goodis, V. Winthrop, and J. M. White, 'Pulpal Responses to Cooling Tooth Temperatures', J Endod 26,5 (2000): 263-7.

30. V. Gopikrishna, G. Pradeep, and N. Venkateshbabu, 'Assessment of Pulp Vitality: A Review', Int J Paediatr Dent 19,1 (2009): 3-15.

31.H. Strobl, G. Gojer, B. Norer, and R. Emshoff, 'Assessing Revascularization of Avulsed Permanent Maxillary Incisors by Laser Doppler Flowmetry', J Am Dent Assoc 134,12 (2003): 1597-603.
32. C. Winzap-Kalin, V. Chappuis, and T. von Arx, '[Laser Doppler Flowmetry for Vitality Testing of Traumatized Maxillary Incisors]', Schweiz Monatsschr Zahnmed 115,1 (2005): 12-7.

33. R. Emshoff, I. Moschen, and H. Strobl, 'Treatment Outcomes of Dental Injury Diagnoses as Related to Blood Flow Measurements from Teeth', J Oral Rehabil 35,3 (2008): 209-17.

34. R. D. Fratkin, D. J. Kenny, and D. H. Johnston, 'Evaluation of a Laser Doppler Flowmeter to Assess Blood Flow in Human Primary Incisor Teeth', Pediatr Dent 21,1 (1999): 53-6.

35. C. Goho, 'Pulse Oximetry Evaluation of Vitality in Primary and Immature Permanent Teeth', Pediatr Dent 21,2 (1999): 125-7.

36. Hüseyin Karayilmaz, and Zuhal Kırzıoğlu, 'Genç Daimi Dişlerin Pulpa Kan Akımı Değișimlerinin Lazer Doppler Flowmetri Ile Değerlendirilmesi', Turkiye Klinikleri Journal of Dental Sciences 16,2 (2010): 129-35.

37. M. Ikawa, M. Fujiwara, H. Horiuchi, and H. Shimauchi, 'The Effect of Short-Term Tooth Intrusion on Human Pulpal Blood Flow Measured by Laser Doppler Flowmetry', Arch Oral Biol 46,9 (2001): 781-7.

38. A. D. Watson, T. R. Pitt Ford, and F. McDonald, 'Blood Flow Changes in the Dental Pulp During Limited Exercise Measured by Laser Doppler Flowmetry', Int Endod J 25,2 (1992): 82-7.

39. J. Ahn, and M. A. Pogrel, 'The Effects of $2 \%$ Lidocaine with 1:100,000 Epinephrine on Pulpal and Gingival Blood Flow', Oral Surg Oral Med Oral Pathol Oral Radiol Endod 85,2 (1998): 197-202.

40. H. S. Chng, T. R. Pitt Ford, and F. McDonald, 'Effects of Prilocaine Local Anaesthetic Solutions on Pulpal Blood Flow in Maxillary Canines', Endod Dent Traumatol 12,2 (1996): 89-95.

41. W. H. Raab, W. Magerl, and H. Muller, 'Changes in Dental Blood Flow Following Electrical Tooth Pulp Stimulation--Influences of Capsaicin and Guanethidine', Agents Actions 25,3-4 (1988): 237-9.

42. E. M. Fernieini, J. D. Bennett, D. G. Silverman, and T. M. Halaszynski, 'Hemodynamic Assessment of Local Anesthetic Administration by Laser Doppler Flowmetry', Oral Surg Oral Med Oral Pathol Oral Radiol Endod 91,5 (2001): 526-30

43. P. Brodin, L. Linge, and H. Aars, 'Instant Assessment of Pulpal Blood Flow after Orthodontic Force Application', J Orofac Orthop 57,5 (1996): 306-9

44. Y. Sano, M. Ikawa, J. Sugawara, H. Horiuchi, and H. Mitani, 'The Effect of Continuous Intrusive Force on Human Pulpal Blood Flow', Eur J Orthod 24,2 (2002): 159-66.

45. H. Babacan, C. Doruk, and A. A. Bicakci, 'Pulpal Blood Flow Changes Due to Rapid Maxillary Expansion', Angle Orthod 80,6 (2010): 113640.

46. T. von Arx, V. Chappuis, C. Winzap-Kalin, and M. M. Bornstein, 'Laser Doppler Flowmetry for Assessment of Anterior Mandibular Teeth in Conjunction with Bone Harvesting in the Symphysis: A Clinical Pilot Study', Int J Oral Maxillofac Implants 22,3 (2007): 383-9.

47. N. P. Chandler, T. R. Pitt Ford, and B. D. Monteith, 'Effect of Restorations on Pulpal Blood Flow in Molars Measured by Laser 
Doppler Flowmetry', Int Endod J 43,1 (2010): 41-6.

48. David A Baab, and P Åke Öberg, 'The Effect of Cigarette Smoking on Gingival Blood Flow in Humans', Journal of clinical periodontology 14,7 (1987): 418-24.

49. H Develioğlu, F Hürmüzlü, and İ Hubbezoğlu, 'Taşkın Dolgularla Papiller Kan Akıșı Arasındaki Ilișkinin Laser Doppler Flowmetre Yardımıyla Değerlendirilmesi', Selçuk Ünv. Dişhek Fak. Derg 12,2 (2002): 52-55.

50. TN Meekin, RF Wilson, DA Scott, M Ide, and RM Palmer, 'Laser
Doppler Flowmeter Measurement of Relative Gingival and Forehead Skin Blood Flow in Light and Heavy Smokers During and after Smoking', Journal of clinical periodontology 27,4 (2000): 236-42.

51. S. Ersahan, F. A. Sabuncuoglu, and E. A. Oktay, 'The Efficacy of Laser Doppler Flowmetry, Electric Pulp Test and Cold Test in Diagnosing Revascularization of Extrusively Luxated Immature Maxillary Incisors', Pak J Med Sci 34,4 (2018): 787-93.

52. Dt Deniz Kökçü, Yrd Doç Dr Murat Yenisey, and Yrd Doç Dr Ahmet Umut Güler, Blood Flow Measurement in Dentistry and Laser Doppler Flowmetry, (Atatürk Üniversitesi Ataturk University, 2014). 